\title{
Anesthesia breathing circuits protected by the DAR Barrierbac $S \circledR$ breathing filter have a low bacterial contamination rate
}

[Les circuits respiratoires d'anesthésie protégés par un filtre DAR Barrierbac $S \circledR$ ont un faible taux de contamination bactérienne]

Daniel P. Vézina MD FRCPC, * Claude A. Trépanier MD FRCPC, ${ }^{\star}$ Martin R. Lessard MD FRCPC, *

Marie Gourdeau MD FRCPC, $\dagger$ Claude Tremblay MD FRCPC

Purpose: In order to reuse the same anesthesia breathing circuit for more than one patient, it has been proposed to add a breathing filter between the Y-piece and the artificial airway. The purpose of this study was to evaluate the in vivo bacterial filtration efficacy of an anesthesia filter in a usual clinical anesthesia setting.

Methods: A sterile DAR Barrierbac $S \circledR$ breathing filter was inserted at the Y-piece of a sterile single-use anesthesia breathing circuit before induction of general anesthesia. At the end of anesthesia, the breathing circuit connector of the filter and of the endotracheal tube connector were cultured separately on growth media (chocolate and blood agar). These were incubated for $48 \mathrm{hr}$ and bacterial identification was conducted using standard methods.

Results: Bacterial cultures were negative on both sides of the filter membrane of I 842 of the 200 I filters studied. Cultures were positive on the patient side of 104 filters. In two of those, the same bacteria were found on both the circuit side and the patient side of the filter. Therefore these data indicate a clinical effectiveness of $99.9 \%$ (confidence interval, Cl 95\%, 99.6-99.998\%), and an in vivo filtration efficacy of $98.08 \%$ (Cl 95\%, 92.54-99.67\%).

Conclusion: Using the upper limit of the $\mathrm{Cl}$, it can be assumed that the practice of using a sterile DAR Barrierbac $S \otimes$ breathing filter for every patient while reusing the anesthesia breathing circuit would result in a cross contamination rate of the breathing circuit lower than once every 250 cases. visait à évaluer l'efficacité de la filtration bactérienne in vivo d'un filtre d'anesthésie dans une situation clinique habituelle.

Méthode : Un filtre respiratoire DAR Barrierbac $S \circledR$ a été inséré à la pièce en $Y$ d'un circuit respiratoire stérile à usage unique avant l'induction de l'anesthésie générale. À la fin de l'anesthésie, le connecteur du filtre du circuit respiratoire et le connecteur de la canule endotrachéale ont été mis en culture séparément dans un milieu de croissance (chocolat et gélose au sang). Ils ont été incubés pendant $48 \mathrm{~h}$ et l'identification bactérienne a été réalisée selon des méthodes standard.

Résultats : Les cultures bactériennes ont été négatives des deux côtés de la membrane filtrante de I 842 des 200 | filtres étudiés. Les cultures ont été positives du côté patient de 104 filtres. Dans deux de ces filtres, on a retrouvé la même bactérie du côté circuit et du côté patient. Ces données indiquent donc une efficacité clinique de $99.9 \%$ (intervalle de confiance IC de $95 \%$, 99,6-99,998 $\%$ ) et une efficacité de filtration in vivo de $98.08 \%$ (IC $95 \%$, 92,54-99,67\%).

Conclusion : En utilisant la limite supérieure de l'IC, on peut supposer que la pratique de l'usage d'un filtre respiratoire stérile DAR Barrierbac $S \circledR$ pour chaque patient alors qu'on réutilise le circuit respiratoire d'anesthésie, pourrait produire un taux de contamination croisée du circuit respiratoire inférieur à un sur 250 cas.

Objectif : Dans le but de réutiliser le même circuit respiratoire d'anesthésie pour plus d'un patient, on a proposé d'ajouter un filtre respiratoire entre la pièce en $Y$ et la canule endotrachéale. L'étude

From the Départements d'anesthésie* et de microbiologie, † Centre hospitalier affilié universitaire de Québec, (hôpital Enfant-Jésus), et service de microbiologie, $\ddagger$ Centre hospitalier universitaire de Québec, $\ddagger$ Université Laval, Quebec, Quebec, Canada.

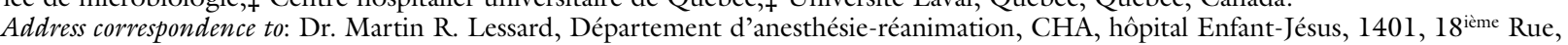
Quebec, Quebec G1J 1Z4, Canada. Phone: 418- 649-5807; Fax: 418-649-5918; E-mail: mrlessard@videotron.ca This study was supported in part by Mallinckrodt DAR

Presented in part at the Residents' competition at the Annual Meeting of Canadian Anesthesiologists' Society, June 1998, Toronto, Ontario, Canad

Accepted for publication March 27, 2001.

Revision accepted May 9, 2001.

CAN J ANESTH $2001 / 48: 8 /$ pp 748-754 
$\mathrm{R}$ ESPIRATORY infections are among the most important causes of nosocomial infection in the postoperative period and are associated with prolonged hospitalisation and increased costs. Contaminated anesthesia apparatus have been implicated as a causative factor of postoperative pulmonary infections. ${ }^{1-4}$ Indeed microorganisms have been isolated in almost every part of the anesthesia breathing system. ${ }^{5,6}$ Thus the current recommendations of both the Centers for Disease Control (CDC) and the American Society of Anesthesiologists (ASA) state that sterile anesthesia breathing material should be used for every patient. ${ }^{7,8}$ According to their recommendations, single-use sterile anesthesia breathing circuits should be used for every patient or, if reusable breathing circuits are used, they must be sterilized or submitted to a high-level disinfection procedure between each patient. ${ }^{7,8}$

Because of increasing concerns about cost containment in health care, it has been suggested that some single-use devices, including disposable anesthesia breathing systems, could be reused for several patients. In order to maintain sterility and to prevent cross infection it has been suggested to place a breathing filter between the Y-piece of the anesthesia breathing circuit and the proximal end of the endotracheal tube. ${ }^{9,10}$ This practice could avoid having to change, sterilize or disinfect the breathing circuits after each use. If the retail price of a breathing filter is significantly lower than the cost of a disposable breathing circuit or the cost of sterilization, this practice could be cost efficient. ${ }^{9}$ However, neither the CDC nor the ASA has endorsed this practice since clinical data supporting its efficacy and safety are lacking. ${ }^{7,8}$ Even if the bacterial and viral filtration efficacy of different breathing filters has been adequately assessed in laboratory investigations, their efficacy and effectiveness to prevent cross infections have not been investigated in the clinical setting. Therefore the purpose of this study was to evaluate, in the usual clinical anesthesia setting, the bacterial filtration efficacy of an anesthesia breathing filter.

\section{Materials}

The study was conducted in the operating room of the Centre hospitalier affilié universitaire de Québec (Hôpital de l'Enfant-Jésus). Over a 26-week period, all daytime cases under general anesthesia were included in the study. The breathing filter studied was the DAR Barrierbac $S \circledR$ (Mallinckrodt DAR, Mirandola, Italy). Each filter was presented in a sterile package. For each case, a new sterile breathing filter was aseptically connected to the Y-piece of a new sterile disposable clear anesthesia breathing circuit of $22 \mathrm{~mm}$ diameter and
$183 \mathrm{~cm}$ length (Trudell Medical Ltd, London, Ontario, Canada) before the induction of general anesthesia. Thereafter, no attempt of any kind was made to guide or alter the management of anesthesia which was conducted in the usual manner by the attending anesthesiologist. The airway could be managed either with an endotracheal tube, a face mask or a laryngeal mask airway according to the preference of the attending anesthesiologist. Data on length and type of surgery, fresh gas flow used, presence of macroscopic secretions in the filter and presence of bronchospasm or cough were collected for each patient.

At the end of anesthesia, the breathing filter was removed from the Y-piece. Both sides of the breathing filter (patient and circuit) were sampled for bacterial culture using the following procedure (Figure). First, the outside of the proximal connector (circuit side) of the breathing filter was disinfected with an alcohol wipe. The inside of the connector was then swabbed avoiding any contact with the filter membrane. Second, the outside of the connector of the endotracheal tube (patient side) was also disinfected with an alcohol wipe and its inside was swabbed, again avoiding any contact with the filter membrane. Both swabs were soaked separately in a trypticase liquid soy broth (TLSO) transport media. These procedures were conducted by specially trained anesthesia technicians and monitored by one of the investigators (D.P.V.). Within three hours of sampling, $100 \mu \mathrm{L}$ of each TLSO were plated on two growth media: chocolate and blood agar. These were incubated at $35 \mathrm{C}$ in a $5 \% \mathrm{CO}_{2}$ atmosphere for $48 \mathrm{hr} .{ }^{11}$ Bacterial identification was conducted using standard microbiological procedures. All samples were processed by the same microbiology technician assigned exclusively to this task.

\section{Data analysis}

Continuous parametric data are presented as mean \pm SD. Bacterial passage through the filter membrane was considered positive when the same microorganism was isolated on both sides of the breathing filter. The clinical effectiveness of a breathing filter to prevent contamination of the anesthesia breathing circuit was calculated using the ratio of bacterial passage through the filter membrane to the total number of filters studied.

$$
\text { clinical effectiveness }=\quad 1-\frac{\text { no. bacterial passage }}{\text { total no. of filters studied }} * 0
$$

The in vivo filtration efficacy of the breathing filter tested was calculated using the ratio of bacterial passage through the filter membrane to the number of 
breathing filters submitted to a definite bacterial challenge (positive bacterial growth on the patient side of the filter).

in vivo filtration efficacy $=$

$$
\text { no. bacterial passage }
$$

$$
\text { no. of challenged filters }
$$
CI.

These data are presented as percentages with 95\%

\section{Results}

Two thousand one (2001) anesthesia breathing filters were studied over a 26-week period. Mean duration of anesthesia was $96.9 \pm 65.3 \mathrm{~min}$. Type of surgery included orthopedic (18\%), general (16\%), gynecological $(16 \%)$, neurosurgery (14\%), otorhinolaryngology (10\%), eye $(7 \%)$, plastic $(6 \%)$, miscellaneous (13\%). Anesthesia was conducted with either endotracheal intubation, a laryngeal mask airway, a face mask, or tracheotomy in $90 \%, 7.8 \%, 1.8 \%, 0.4 \%$ of cases respectively. No complication related to the breathing filter (e.g., obstruction, high ventilation pressure, air leak) was observed. After the results of bacterial growth were known, a post-hoc allocation of the filters to four groups was done. In group A ( $n=1842$ filters), bacterial growth was negative on both sides of the filter (circuit and patient sides). In group B ( $n=55$ filters), bacterial growth was positive on the circuit side and negative on the patient side. In group C ( $n=99$ filters), bacterial growth was present on the patient side and negative on the circuit side. Bacterial species isolated in groups B and C are reported in Table I. Finally, in group $\mathrm{D}$ ( $n=$ five filters), bacterial growth was present on both the circuit and patient sides (Table II). Of these, three filters grew different bacterial species on the circuit and the patient sides, and two filters grew the same bacteria on both sides of the filter.

Thus, according to the definition mentioned above, positive bacterial passage through the filter membrane occurred in these last two filters only. The first one grew Streptococcus alpha hemolytic. It was used during a plastic surgery case lasting $110 \mathrm{~min}$. The airway was managed with an endotracheal tube, fresh gas flow was more than $1 \mathrm{~L} \cdot \mathrm{min}^{-1}$, and the case was uneventful. The second filter grew mixed oropharyngeal flora. It was used during a general surgery case lasting $105 \mathrm{~min}$. The airway was also managed with an endotracheal tube during an uneventful low flow anesthesia. No coughing or bronchospasm occurred and no secretion was observed in the endotracheal tube in either case.

Therefore the positive bacterial passage through the membrane of two out of 2001 breathing filters tested represents a clinical effectiveness of $99.9 \%$ (CI
TABLE I Bacterial identification in groups B and C

\begin{tabular}{lll}
\hline GROUP B & & \\
Bacterial identification & Number & Percentage \\
Coagulase-negative staphylococci & 32 & 58 \\
Streptococcus species & 20 & 36 \\
Other & 3 & 6 \\
GROUP C & & \\
Bacterial identification & Number & Percentage \\
Staphylococcus epidermidis & 36 & 36 \\
Mixed oropharyngeal flora & 34 & 34 \\
Streptococcus species & 7 & 7 \\
Fungus & 3 & 3 \\
Other & 20 & 20 \\
\hline
\end{tabular}

Group B=bacterial growth positive on the circuit side only; group $\mathrm{C}=$ bacterial growth positive on patient side only.

\begin{tabular}{|c|c|c|}
\hline Filter & Patient side & Circuit side \\
\hline 1 & Diphteroids & Enterococcus faecalis \\
\hline 2 & Staphylococcus capitis & $\begin{array}{l}\text { Staphylococcus } \\
\text { epidermidis }\end{array}$ \\
\hline 3 & Staphylococcus epidermidis & Staphylococcus simulans \\
\hline 4 & Streptococcus alpha hemolytic & $\begin{array}{l}\text { Streptococcus alpha } \\
\text { hemolytic }\end{array}$ \\
\hline 5 & Mixed oropharyngeal flora & Mixed oropharyngeal flora \\
\hline
\end{tabular}

TABLE II Bacterial identification in group D

Group $\mathrm{D}=$ bacterial growth positive on both the circuit and patient sides.

95\%=99.6-99.998\%). Taking into account only the filters that were submitted to a documented bacterial challenge (groups $\mathrm{C}$ and $\mathrm{D})$, the in vivo filtration efficacy of the breathing filter was 98.08 (CI 95\%=92.54-99.67\%).

\section{Discussion}

According to a survey done across Canada, the practice of using breathing filters and reusing the same anesthesia breathing circuit for multiple patients appears to be quite prevalent $(29 \%$ of the institutions who answered the survey). ${ }^{12}$ For both cost-saving and time-saving purposes, this practice is an appealing alternative to the standard practice of using a sterile or high level disinfected breathing circuit for every patient. However this practice is endorsed neither by the CDC nor the ASA.7.8 In the 1997 Guidelines for prevention of nosocomial pneumonia, the CDC makes the following recommendations regarding anesthesia breathing circuits: "Clean and then sterilize or subject to high-level liquid chemical disinfection or pasteurization reusable components of the breathing system or patient circuit (e.g., tracheal tube or face mask, inspiratory and expiratory breathing tubing, Y-piece, reservoir bag, humidifier, and humidifier tubing) 


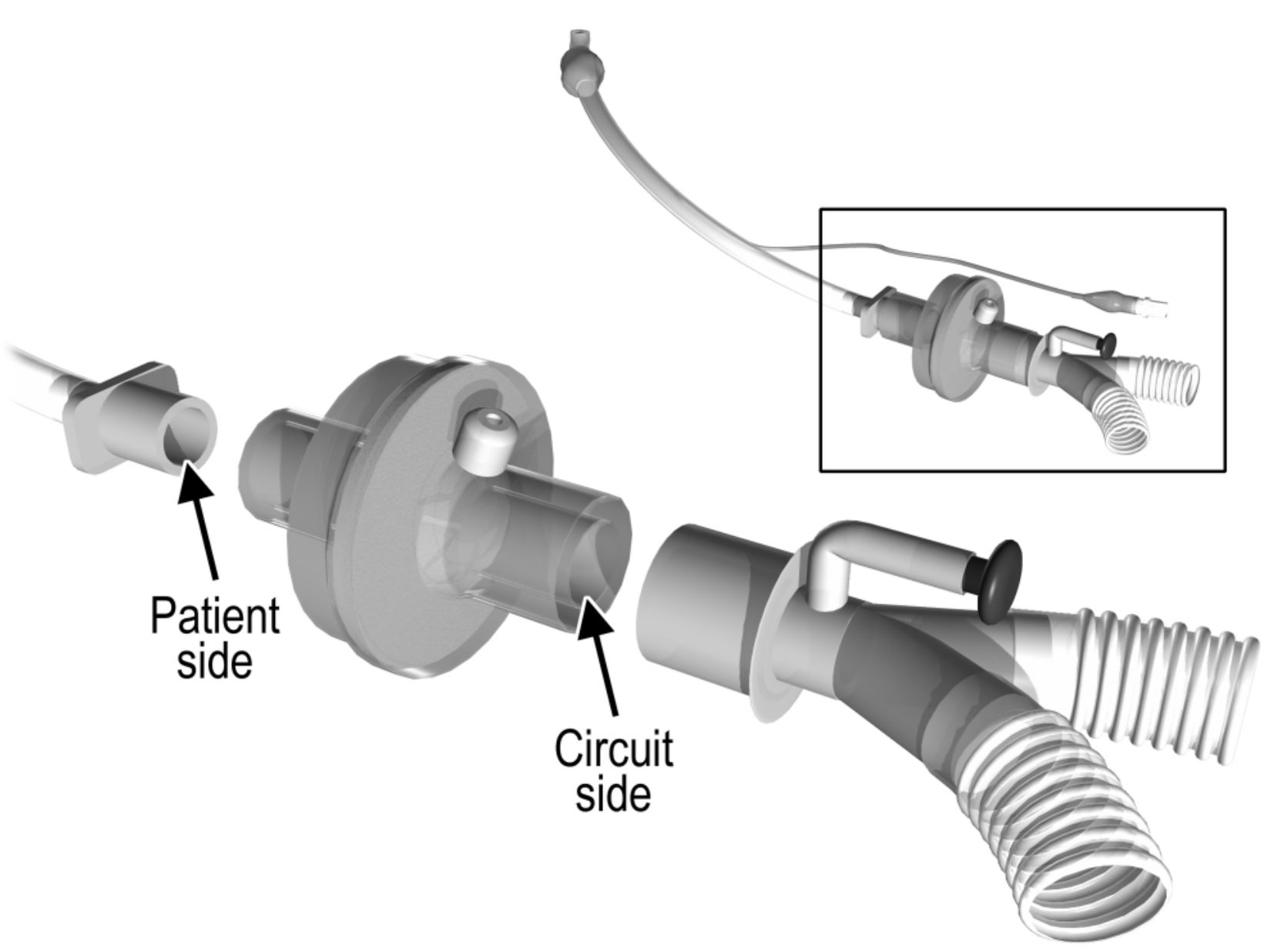

FIGURE Drawing of a DAR Barrierbac S® breathing filter inserted between the Y-piece of the anesthesia breathing circuit and the proximal end of the artificial airway (endotracheal tube, face mask, laryngeal mask airway). Arrows indicate the sampling sites of the patient side and the circuit side of the breathing filter.

between uses on different patients" and "No recommendation for placing a bacterial filter in the breathing system or patient circuit of anesthesia equipment". 7 The Committee on Occupational Health of Operating Room Personnel of the ASA has endorsed these recommendations while stressing the lack of clinical data on the issue. ${ }^{8}$ Obviously, studies assessing the efficiency and the safety of such a practice are warranted.

The goal of this study was to evaluate the in vivo bacterial filtration efficacy and the clinical effectiveness of one of the anesthesia breathing filters available in Canada. The main finding is that, although the contamination rate was very low, the breathing filter studied did not completely prevent contamination of the breathing circuit. In this study, the clinical effective- ness was $99.9 \%$ (CI 95\%= 99.6-99.998\%). Using the lower limit of the CI of clinical effectiveness, it can be assumed that the practice of using a sterile DAR Barrierbac $S \AA$ breathing filter for every patient while reusing the anesthesia breathing circuit would result in contamination of the breathing circuit in less than once every 250 cases. It must be stressed that this figure does not represent the risk of acquiring a bacterial respiratory tract infection. This risk is most likely lower since the presence of bacteria in the breathing circuit does not mean that the next patient using the same breathing circuit will become contaminated or develop a respiratory tract infection. ${ }^{13,14}$ The risk of acquiring a respiratory tract infection from a contaminated anesthesia breathing circuit is determined by the bacterial load and the host defence mechanisms. 
Besides, it can be expected that the breathing filter will have some efficacy for downstream protection of the patient from a contaminated breathing circuit therefore reducing further the bacterial load. ${ }^{13}$

A few other studies have evaluated anesthesia breathing filters in the anesthetic setting, although with much smaller sample sizes. Pottecher et al. compared the contamination rate of the Y-piece of $\mathbf{5 0}$ breathing circuits protected by a filter to that of 45 circuits without a filter. In both cases, they found a high contamination rate $(<40 \%)$ but with a very low bacterial titer. ${ }^{15}$ Luttropp et al. studied 55 bacterial filters of three different types (Pall Ultipor BB $50 \AA$, Gibeck Humid-Vent ${ }^{\circledR}$ and Pharma BACT-HME $\left.{ }^{\circledR}\right)$ placed between the Y-piece and the endotracheal tube during low flow anesthesia. At the end of anesthesia, both sides of the filters were sampled. They found no positive bacterial culture on the patient side of the filters (100\% effectiveness). ${ }^{16}$ Callery et al. reported two cases of bacterial contamination among 96 breathing circuits protected by breathing filters. ${ }^{17}$ Finally, Rathgeber studied three different types of filters with heat and moisture exchange (HME) properties (DAR Hygrobac ${ }^{\circledR}$, Hygrobac $S \circledR$ and Medisize Hygrovent $S($ ) during general anesthesia. They reported a $100 \%$ effectiveness of the 200 filters tested. ${ }^{18}$

In the present study, although a large sample size was used, a large number of filters were not contaminated on the patient side (groups A and B, $n=1897$ ). Thus, definitive challenge was limited to filters which had bacterial growth on the patient side (groups C and D, $n=104$ ). Since most surgical procedures were elective, in healthy patients whose trachea should have a low rate of bacterial colonisation, this low rate of effective bacterial challenge $(5.02 \%)$ was not unexpected. ${ }^{18}$ It was actually pivotal in the selection of a large sample size. Filters in group B $(n=55)$ were contaminated on the circuit side only. These filters grew mostly skin and oral flora and these are probably the result of external contamination either during sampling or during the manipulations associated with mask ventilation and tracheal intubation. This illustrates that some anesthesia breathing circuits will get contaminated during the normal course of anesthesia, thus re-emphasizing the importance to sterilize or disinfect to a high degree reusable breathing circuits between patients. Filters in group C $(n=99)$ were positive on the patient side only and grew either skin or oropharyngeal flora. In this group, the anesthesia breathing circuit was effectively protected from contamination. Filters in group D $(n=5)$ had bacterial growth on both sides. However, in three of them bacteria on the patient side were different from those on the circuit side. Here again, external contamination is likely. The last two filters of group $\mathrm{D}$ grew the same genera on both sides. According to the definition used, this represents positive contamination of the breathing circuit from the patient respiratory tract through a deficient filter membrane. In these two cases, bacterial passage through the filter may have occurred because of the limited efficacy of the filtration media or because of a defect in the filter membrane. However, failure of the filters cannot be ascertained since neither precise species identification or bacterial DNA typing were done. Thus, external contamination with the same bacteria on both sides of the filter is also possible.

Laboratory studies have reported filtration efficacy exceeding $99.99 \%$ for anesthesia breathing filters with and without HME properties. ${ }^{19-22}$ However, it is difficult to compare laboratory studies to a clinical study like this one. First the conditions encountered in the clinical anesthetic setting where the filters are submitted to moisture, secretions, cough, bidirectional airflow and pressure changes differ from the laboratory settings. Second, in laboratory studies, the performance of anesthesia breathing filters is usually reported as the titer reduction value and the bacterial removal efficiency. Although such data are useful to compare the performance of different filters, they are insufficient to assess the performance of filters in clinical anesthesia practice. The use of breathing filters is proposed in order to maintain the sterility of the anesthesia breathing circuits, and any contamination of the breathing circuit should be considered a failure of the breathing filter. Thus laboratory studies must be interpreted with caution and the high filtration efficacy reported must be confirmed in the clinical setting before any recommendation on the widespread use of breathing filters can be made.

Ideally, the clinical safety and efficiency of reusing breathing circuits with breathing filters should be demonstrated by a study of the incidence of postoperative respiratory tract infection compared to the incidence associated with the standard practice of using sterile equipment. However such a study can hardly be conducted because the incidence of respiratory tract infection in the general surgical population is low and its causes are numerous. Therefore a surrogate endpoint such as the incidence of bacterial contamination of the breathing circuit must be used, knowing that only an undetermined fraction of the contaminated breathing circuits might cause a respiratory tract infection. Two other methodological limitations of this study must be considered. First, this study tested a single model of anesthesia breathing filter. The DAR 
Barrierbac $S \circledR$ was selected among filters available on the market at the time of the study because of its excellent bacterial filtration efficiency (>99.9999\%) reported from laboratory studies, ${ }^{19,20}$ its small size and low dead space volume compatible with use in the clinical setting, and its retail sale price significantly lower than the cost of a disposable anesthesia breathing circuit. Other models with different construction or filtration material (e.g., filters with HME characteristics) might perform differently. Second, it must be stated that this study was limited to the bacterial filtration efficacy of the breathing filter tested and our results cannot be extrapolated to virus, fungi or mycobacteria. Recently, an investigation on an outbreak of hepatitis $\mathrm{C}$ infection in a private operating facility pointed to a contaminated anesthesia breathing circuit as the possible source of infection. ${ }^{4}$ Also, tuberculosis is still a great concern in all fields of health care including anesthesia. ${ }^{23}$

In summary, this study tested a large sample of an anesthesia breathing filter in the usual anesthesia setting and showed that the practice of using a sterile breathing filter for every patient while reusing the anesthesia breathing circuit might fail and result in contamination of the breathing circuit in less than one every 250 cases. However, given the limitations mentioned above, we believe that it would be premature to conclude that the DAR Barrierbac S® breathing filter allows the reuse of anesthesia breathing circuits without high level disinfection or sterilization.

\section{Acknowledgements}

The authors thank Dr. Gilles Chiniara for producing the illustration of the Figure, Mrs. Yolande Pesant microbiology technician, the anesthesia personnel of hôpital de l'Enfant-Jésus for their interest and cooperation in this study, and Line Godin for secretarial assistance.

\section{References}

1 Tinne JE, Gordon AM, Bain WH, Mackey WA. Crossinfection by pseudomonas aeruginosa as a hazard of intensive surgery. Br Med J 1967; 4: 313-5.

2 Olds JW, Kisch AL, Eberle BJ, Wilson JN. Pseudomonas aeruginosa respiratory tract infection acquired from a contaminated anesthesia machine. Am Rev Respir Dis 1972; 105: 629-32.

3 Albrecht WH, Dryden GE. Five-year experience with the development of an individually clean anesthesia system. Anesth Analg 1974; 53: 24-8.

4 Chant K, Kociuba K, Crone S, et al. Investigation of possible patient-to-patient transmission of hepatitis $\mathrm{C}$ in a hospital. NSW Public Health Bull 1994; 5: 47-51.

5 Craven DE, Goularte TA, Make BJ. Contaminated condensate in mechanical ventilator circuits. A risk factor for nosocomial pneumonia? Am Rev Respir Dis 1984; 129: 625-8.

6 Murphy PM, Fitzgeorge RB, Barrett RF. Viability and distribution of bacteria after passage through a circle anaesthetic system. Br J Anaesth 1991; 66: 300-4.

7 Public Health Service Centers for Disease Control. Guidelines for prevention of nosocomial pneumonia. MMWR 1997; 46 (RR-1): 1-79.

8 American Society of Anesthesiologists. Committee on Occupational Health of Operating Room Personnel. Recommendations for Infection Control for the Practice of Anesthesiology, 2nd ed., Park Ridge, IL: American Society of Anesthesiologists, 1998.

9 Berry AJ, Nolte FS. An alternative strategy for infection control of anesthesia breathing circuits: a laboratory assessment of the Pall HME filter. Anesth Analg 1991; 72: 651-5.

10 Ibrahim JJ, Perceval AK. Contamination of anaesthetic tubing - a real hazard? Anaesth Intensive Care 1992; 20: 317-21.

11 Reisner BS, Woods GL, Thomson RB Jr, Larone DH, Garcia LS, Shimizu RY. Specimen processing. In: Murray PR, Baron EJ, Pfaller MA, Tenover FC, Yolken RH (Eds.). Manual of Clinical Microbiology, 7th ed., Washington DC: ASM Press, 1999: 64-104.

12 Alfieri N, Armstrong P. Patient circuit components of anesthetic equipment between uses on different patients (Letter). Can J Infect Control 1995; 10: 61.

13 Hogarth I. Anaesthetic machine and breathing system contamination and the efficacy of bacterial/viral filters. Anaesth Intensive Care 1996; 24: 154-63.

14 Herwaldt LA, Pottinger JM, Coffin SA. Nosocomial infections associated with anesthesia. In: Mayhall CG (Ed.). Hospital Epidemiology and Infection Control, 2nd ed. Philadelphia: Lippincott Williams \& Wilkins, 1999: 847-74.

15 Pottecher B, Eberhardt R, Kieny MT, et al. Evaluation du rapport coût-efficacité des filtres Pall BB 22 15® dans la protection bactérienne des circuits d'anesthésie. Agressologie 1990; 8: 553-6.

16 Luttropp HH, Berntman L. Bacterial filters protect anaesthetic equipment in a low-flow system. Anaesthesia 1993; 48: 520-3.

17 Callery S, Jaskolka J, Holwerda A, Groves D. Safety and cost-effectiveness of filter protected, multi-use anaesthetic circuits. CHICA-Canada, National Education Conference. Can J Infect Control 1996; 11: 75 (abstract).

18 Rathgeber J, Kietzmann D, Mergeryan H, Hub R, Züchner K, Kettler D. Prevention of patient bacterial contamination of anaesthesia-circle-systems: a clinical study of the contamination risk and performance of different heat and moisture exchangers with electret filter (HMEF). Eur J Anaesthesiol 1997; 14: 368-73. 
19 Borghi V, Tavio M, Zoboli G, Sabbatini A, Squadrini F Comparative evaluation of the bacteria and virus

removal efficiency of filters used in anaesthesia and intensive care. Chest 1986; 107: 1471-5.

20 Borghi V, Ferrari E, Vacondio P, Meacci M, Squadrini F. Bacterial removal efficiency of filters-HME for anaesthesia and intensive care in 24-hour tests. Acta Anaesth Italica 1992; 43(Suppl. 1): 93-7.

21 Holton J, Webb AR. An evaluation of the microbial retention performance of three ventilator-circuit filters. Intensive Care Med 1994; 20: 233-7.

22 Vandenbroucke-Grauls CMJE, Teeuw KB, Ballemans K, Lavooij C, Cornelisse PB, Verhoef J. Bacterial and viral removal efficiency, heat and moisture exchange properties of four filtration devices. J Hosp Infect 1995; 29: 45-56.

23 McCray E, Weinbaum CM, Braden CR, Onorato IM.

The epidemiology of tuberculosis in the United States. Clin Chest Med 1997; 18: 99-113.

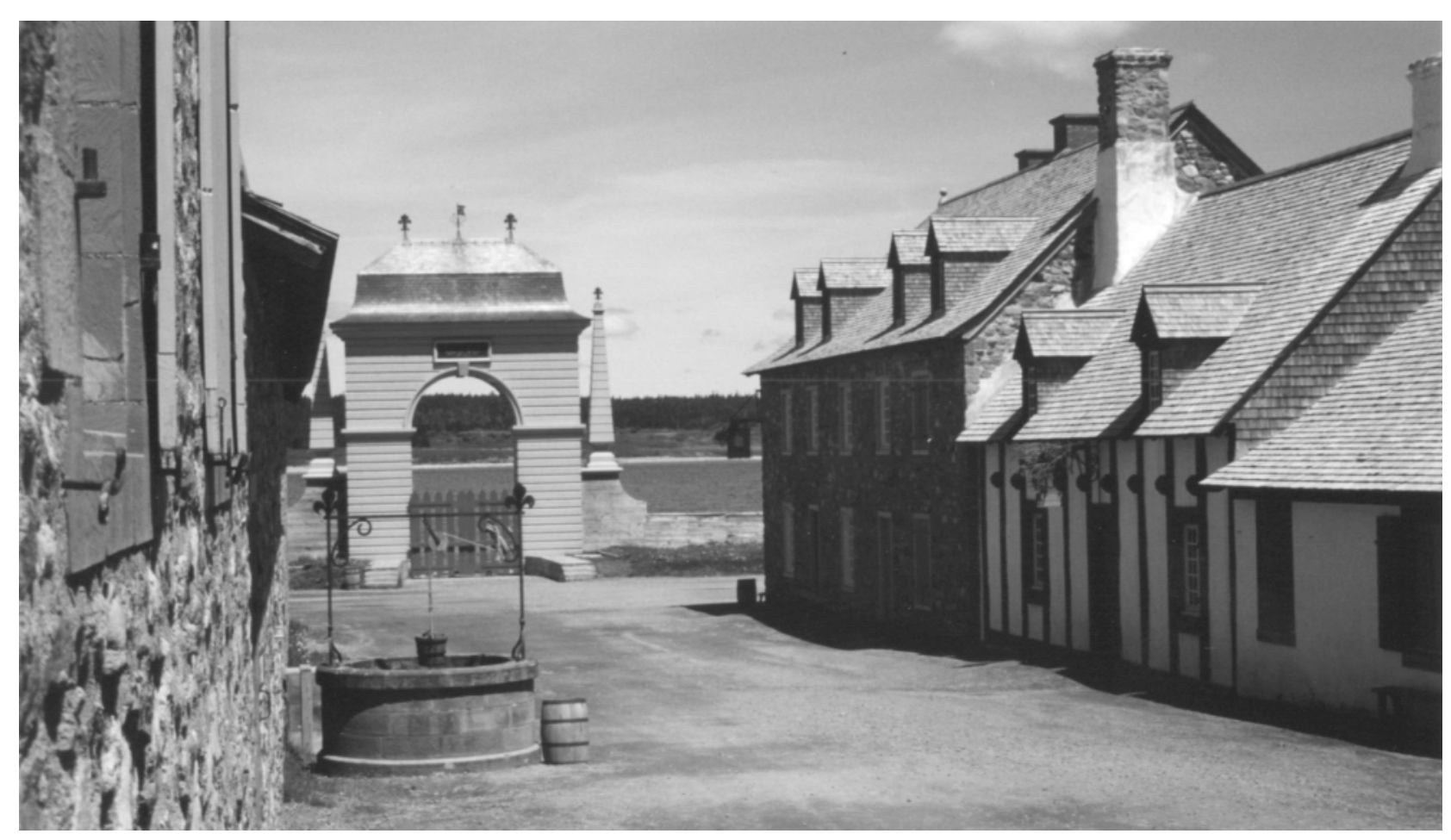

Forteresse de Louisbourg - Nova Scotia 